INTERNATIONAL HIGHER EDUCATION, No. 67, Spring, 2012

Pages 21-23

\title{
Widening Participation in Higher Education in Ghana and Tanzania
}

\author{
LOUISE MORLEY
}

Louise Morley is a professor at the Centre for Higher Education and Equity Research, at the University of Sussex, UK. E-mail: L.Morley@sussex.ac.uk. For additional analysis, see www.sussex.ac.uk/education/cheer/wphegt.

An interrogation under way is whether policies for widening participation in subSaharan Africa are working. That was one of the key questions addressed by the research project Widening Participation in Higher Education in Ghana and Tanzania: Developing an Equity Scorecard. Research teams-at the Universities of Sussex, UK; Cape Coast, Ghana; and Dar es Salaam, Tanzania-found that the policies were working in the sense of increasing the overall number of students, especially women, participating in higher education. However, they found that poorer and mature students were still absent from many of the programs investigated in one public and one private university, in both Ghana and Tanzania. The universities included in the study did have quotas for students from disadvantaged backgrounds, but failed to fill them or monitor how many poorer students were participating and completing their studies. Students who did succeed, in entering university, shared helpful insights into their lived experiences. 


\section{STUdent Voices}

An original aspect of the study contained two hundred student life-history interviews about their experiences of primary, secondary, and higher education, with questions about their motivations, transitions, support, decision making and first impressions of higher education, its impact on them, and their future plans. Students from a diversity of backgrounds, including underrepresented groups-such as, women, mature, low socioeconomic status, and disabled students-discussed entering and experiencing higher education. Financial concerns ran through the entire study. Many studentsespecially those from low socioeconomic backgrounds-reported that their participation had been entirely dependent on loans and bursaries. Mature students reported the strains and stresses of earning, while learning, often with extended family responsibilities.

The evidence revealed many committed and caring individuals working in higher education, in both African countries, and students appreciated the support that they had received from lecturers, counselors, and advisers. However, a significant number complained of poor-quality tuition and a lack of learning resources and facilities, including libraries and information technology. Disabled students were particularly affected by low-standard and often inaccessible facilities. Many students reported problems with large classes and overcrowded classrooms and wanted fewer large-scale transmission lectures and more interactive and engaging pedagogies.

An area that attracted plenty of attention was assessment. Not only was it the focal point for considerable joy or sadness; many students felt that the process itself was often precarious and lacking in transparency. A common concern was that lecturers did 
not seem accountable to any wider-quality assurance procedures and often appeared to make unilateral, tardy, and inconsistent decisions about grades and curriculum content.

\section{GENDER INEQUALITIES}

The transformative and instrumental potential of higher education was noted by many women students-securing financial independence, professional identity, and status. However, while the numbers of women as undergraduate students were increasing, there were questions about the gender inequalities and discrimination that many women, who once entered, experienced. Sexual harassment was discussed by staff and students in both countries, especially in relation to some male tutors pressurizing female students for sex, in return for grades. This led to extreme difficulties for female students' physical and mental well-being and deterred them from seeking tutorial support from male tutors or making themselves visible in class.

Women students also reported how they were pressured by male students, sexually and socially, with the men appropriating female students' domestic labor for cooking, laundry, etc. This disturbed and distracted women from their studies and left them with limited lifestyle choices. Having a boyfriend was the norm, and those women who did not succumb to this pressure were stigmatized and/or marginalized.

\section{BECOMING A SOMEBODY}

In spite of their often serious concerns about quality and dangers, students generally felt that higher education had transformed their social identities and potential. For many, it represented a means of "becoming a somebody." They reported that being a 
student had enhanced their sense of self-efficacy and self-esteem, and many wanted to use their newfound social and intellectual capital, for national economic and social development. Others simply wanted the "good life" and an escape route from rural and urban poverty. Any negative experiences seemed to be erased by their aspirations to succeed in societies, where they believed that being a graduate guaranteed comfortable lifestyles. Many wanted to continue into postgraduate study.

\section{DOING MORE WITH LesS}

The interviews with two hundred staff and policymakers often highlighted capacity challenges and how widening participation policies were introduced, without additional resources. They talked extensively about the impact of poverty on student participation and the crucial role of the loans systems in enabling poorer students to gain access and successfully complete their studies. They suggested that Education for All policies and Millennium Development Goals needed to be more integrated in higher education policy; currently, all the policy emphasis was based on including more socially disadvantaged young people in basic, rather than, higher education.

There was significant pride in the increase of women students, especially in science programs. Many of these interviewees felt that this could be attributed to the affirmative-action efforts, which had been introduced and funded by international donors. However, many noted the absence of effective data and management information systems that would allow them to monitor and evaluate access, retention, and achievement of different groups of students. 


\section{MAPPING INEQUALITIES}

A distinctive feature of the study was to set the interviews alongside statistical data. One-hundred equity scorecards were compiled largely from raw data on admission/access, retention, completion, and achievement, for four programs of study in relation to three structures of inequality: gender, socioeconomic status, and age. They yielded a nuanced overview of the intersected effects of gender, age, and socioeconomic status and revealed a number of facts that often contradicted narrative accounts. Most programs enrolled few (or not any) low socioeconomic-status students. Low socioeconomic-status students who were present tended to be on programs with lowexchange rates in the labor market. However, once given the chance to enter higher education, fewer low socioeconomic-status students withdrew, and they performed as well as, and sometimes better than, other groups. The group most at risk of withdrawal were mature students. Women, especially low socioeconomic-status and mature women, were still underrepresented on science programs, but more women were entering private, than public, universities.

This research project illustrated how there is still a toxic correlation between poverty and access to higher education. Unequal geographies of knowledge and some archaic patterns of participation in higher education were found in the two countries. Globally, participation rates are rising but not from a range of social groups, in Ghana and Tanzania. For many, widening participation was seen in relation to quantitative change of one particular group, usually women, into science subjects. There was less policy engagement with qualitative experiences of students who once entered, with monitoring educational outcomes including retention and completion, or with 
intersectionality of social identities. The findings raised questions about the need to intersect quality and equality and how the value of higher education should be considered in terms of wealth distribution and poverty alleviation, as well as wealth creation. 